\title{
Vitamin D deficiency as a risk factor for cystic fibrosis-related diabetes in the Scandinavian Cystic Fibrosis Nutritional Study
}

\author{
T. Pincikova • K. Nilsson • I. E. Moen • G. Fluge • \\ A. Hollsing • P. K. Knudsen • A. Lindblad • L. Mared • \\ T. Pressler $\cdot$ L. Hjelte • \\ on behalf of the Scandinavian Cystic Fibrosis Study \\ Consortium (SCFSC)
}

Received: 19 January 2011 / Accepted: 26 July 2011 /Published online: 7 September 2011

(C) Springer-Verlag 2011

\begin{abstract}
Aims/hypothesis Many cystic fibrosis patients are vitamin D-insufficient. Cystic fibrosis-related diabetes is a major complication of cystic fibrosis. The literature suggests that vitamin D might possess certain glucose-lowering properties. We aimed to assess the relationship between vitamin D and cystic fibrosis-related glucose intolerance.

Methods We enrolled 898 cystic fibrosis patients from Sweden, Norway and Denmark. Vitamin D intake was assessed using a seven-day food record. Serum 25hydroxyvitamin $\mathrm{D}$ (s25OHD) and $\mathrm{HbA}_{1 \mathrm{c}}$ were measured, and an OGTT was carried out. Multiple linear and logistic
\end{abstract}

Electronic supplementary material The online version of this article (doi:10.1007/s00125-011-2287-1) contains peer-reviewed but unedited supplementary material, including a list of members of the

Scandinavian Cystic Fibrosis Study Consortium, which is available to authorised users.

T. Pincikova $(\varangle) \cdot K$. Nilsson $\cdot$ L. Hjelte

Stockholm CF Centre, B 59, Karolinska Institutet,

Karolinska University Hospital Huddinge,

14186 Stockholm, Sweden

e-mail: Terezia.Pincikova@ki.se

I. E. Moen • P. K. Knudsen

National Centre for Cystic Fibrosis,

Oslo University Hospital Ullevaal,

Oslo, Norway

G. Fluge

Cystic Fibrosis Centre, Department of Paediatrics,

Haukeland University Hospital,

Bergen, Norway regressions were used for $\mathrm{HbA}_{1 \mathrm{c}}$ and cystic fibrosis-related diabetes/OGTT result as outcome variables, respectively. Each model was controlled for country, and for known cystic fibrosis-related diabetes risk factors: age, sex, genotype, liver dysfunction, long-term corticosteroid treatment, and lung and pancreatic function.

Results Degree of vitamin D insufficiency (OR 1.36; $p=0.032$ ) and $\mathrm{s} 25 \mathrm{OHD}<30 \mathrm{nmol} / \mathrm{l}(\mathrm{OR} 1.79 ; p=0.042)$ were significant risk factors for cystic fibrosis-related diabetes. Accordingly, $\mathrm{HbA}_{1 \mathrm{c}}$ value was positively associated with $\mathrm{s} 25 \mathrm{OHD}<$ $30 \mathrm{nmol} / 1$ and $<50 \mathrm{nmol} / \mathrm{l}$, as well as with degree of vitamin D insufficiency (adjusted $R^{2}=20.5 \%$ and $p<0.05$ in all).

\author{
A. Hollsing \\ Uppsala Cystic Fibrosis Centre, KBH, \\ Uppsala University Hospital, \\ Uppsala, Sweden
}

\section{A. Lindblad}

The West Swedish CF Centre, Sahlgrenska University Hospital, Gothenburg, Sweden

L. Mared

Heart and Lung Centre, Lund University Hospital,

Lund, Sweden

T. Pressler

Cystic Fibrosis Centre, Department of Paediatrics,

Copenhagen University Hospital,

Copenhagen, Denmark 
In subgroup analyses, $\mathrm{s} 25 \mathrm{OHD}<30 \mathrm{nmol} / 1$ determined the $\mathrm{HbA}_{1 \mathrm{c}}$ value in paediatric patients (adjusted $R^{2}=20.2 \%$; $p=0.017$ ), but not in adults.

Conclusions/interpretation Vitamin D status is associated with $\mathrm{HbA}_{1 \mathrm{c}}$ and diabetes in cystic fibrosis, particularly in children. The study justifies prospective studies on the proposed role of vitamin D deficiency in the pathophysiology of diabetes mellitus.

Keywords Cystic fibrosis $\cdot$ Diabetes $\cdot$ Food record $\cdot \mathrm{HbA}_{1 \mathrm{c}}$. Vitamin D

Abbreviations
$\begin{array}{ll}\text { 25OHD } & \text { 25-Hydroxyvitamin D } \\ \text { CFRD } & \text { Cystic fibrosis-related diabetes } \\ \text { MLR } & \text { Multiple linear regression } \\ \text { s25OHD } & \text { Serum 25-hydroxyvitamin D }\end{array}$

\section{Introduction}

Cystic fibrosis is the most common life-shortening autosomal recessive condition in people of European descent [1]. The most frequently appearing disease-causing mutation is F508del. The affected gene codes for a chloride channel situated on membranes of epithelial cells. Thus, its defect results in inappropriately thick mucus and malfunctioning of epithelial organs, such as lungs, pancreas and liver [2]. The major cause of morbidity and mortality is progressive pulmonary disease associated with chronic bacterial infection and inflammation [3].

The majority of children and adults with cystic fibrosis worldwide are vitamin D insufficient, irrespective of their exocrine pancreatic function [4-7]. However, there is as yet no evidence for a benefit of vitamin D supplementation in cystic fibrosis, not even for bone health [8]. Many in vitro and clinical descriptive studies support a role for vitamin D in the pathogenesis of both type 1 and type 2 diabetes, which have been reviewed in detail elsewhere [9]. Vitamin D supplementation has been associated with a decreased incidence of type 1 diabetes [10] and plasma 25hydroxyvitamin D (25OHD) has been described as being associated with type 2 diabetes [11]. The exact molecular pathways are not completely understood but vitamin D has been suggested to act via its immunomodulatory effects in type 1 diabetes $[12,13]$ and to increase insulin secretion and peripheral insulin sensitivity in type 2 diabetes $[14,15]$.

With improving medical care, survival increases and long-term complications of cystic fibrosis become more prevalent. The most common complication is cystic fibrosis-related diabetes (CFRD), with a prevalence of 33\% in some populations of patients with cystic fibrosis [16]. CFRD is associated with inferior lung function and earlier death [16-19]. The loss of pancreatic beta cells as a result of pancreatic fibrosis is thought to be one of the principal causes of diabetes in cystic fibrosis, but its aetiology remains unclear. It clearly shares pathological features both with type 1 and type 2 diabetes [20]. It is generally agreed that CFRD primarily results from an insulin-insufficient state, which is aggravated by worsening insulin resistance [21].

Therefore, it is reasonable to hypothesise that the known high prevalence of vitamin D insufficiency in patients with cystic fibrosis may represent a risk factor for the development of CFRD. To the best of our knowledge, there are no reports on the relation between vitamin D and CFRD. Simultaneously, the high prevalence of both diabetes mellitus and vitamin D insufficiency among patients with cystic fibrosis renders this population suitable for studying the suggested glucose-lowering effect of vitamin D. We therefore examined the associations of vitamin D intake and vitamin $\mathrm{D}$ status with $\mathrm{HbA}_{1 \mathrm{c}}$, diagnosis of CFRD, OGTT result and $\mathrm{HbA}_{1 \mathrm{c}}$-defined diabetes mellitus in a welldefined cohort of Scandinavian patients with cystic fibrosis.

\section{Methods}

Study cohort This study used data collected in the Scandinavian Cystic Fibrosis Nutritional Study. It is a cross-sectional multi-centre study, in which seven cystic fibrosis centres (Stockholm, Gothenburg, Lund, Uppsala, Copenhagen, Oslo and Bergen) enrolled 898 patients with cystic fibrosis during an inclusion period from 5 September 2003 to 25 May 2006. The study was approved by the regional ethics committees in each country. All the adult patients and parents of all the paediatric patients gave informed written consent. In the nutritional study we previously assessed the relationship between vitamin $\mathrm{D}$ and serum total $\operatorname{IgG}[22]$. We now used the data collected to analyse vitamin $\mathrm{D}$ as a possible risk factor for CFRD.

Vitamin D intake assessment A 7 day food record was used to quantify daily food vitamin $\mathrm{D}$ intake in patients $\geq 4$ years of age (406 patients). A dietitian specialising in cystic fibrosis provided instructions on how to complete the nationally designed and validated pre-coded forms. Response rates were $76-86 \%$ [22]. The food records have been described in detail previously [22-24].

Dietitians calculated daily supplemented vitamin D intake from the intake of various vitamin and mineral supplements (730 patients). At the time of the study there was no uniform vitamin $\mathrm{D}$ supplementation policy and serum 25OHD (s25OHD) was not monitored. Vitamin D was given in the form of various multivitamin preparations, sometimes combined with a more specific vitamin D supplement or fish liver oil. Total vitamin D intake per 
day was quantified as daily food plus daily supplemented vitamin D intake (389 patients). All vitamin D intake variables were further adjusted to vitamin $\mathrm{D}$ intake per $\mathrm{kg}$ body weight, to adjust for the large variation in patients' body weight $(6.1-131.0 \mathrm{~kg})$.

s25OHD and vitamin D insufficiency classification Serum vitamin D was measured as $\mathrm{s} 25 \mathrm{OHD}$ at inclusion. All the collected samples were analysed at the Research Laboratory, Department of Paediatrics, Haukeland University Hospital in Bergen. A modified version of highperformance liquid chromatography with a UV detection method, described by Aksnes, was used [25]. The method determines the sum of $25 \mathrm{OHD}_{2}$ and $25 \mathrm{OHD}_{3}$, and provides results that are comparable with radioimmunoassay or liquid chromatography-tandem mass spectrometry [26, 27; L. Aksnes, personal communication].

s25OHD was used as a measure of vitamin D status, and four degrees of vitamin $\mathrm{D}$ insufficiency were defined according to s25OHD (nmol/1) as follows: $\mathrm{s} 25 \mathrm{OHD} \geq 75$ (degree 0 ); $50 \leq \mathrm{s} 25 \mathrm{OHD}<75$ (degree 1); $30 \leq \mathrm{s} 25 \mathrm{OHD}<50$ (degree 2); $\mathrm{s} 25 \mathrm{OHD}<30$ (degree 3 ). In addition, all patients were classified either as ' 0 ' (being above) or as ' 1 ' (being below) with respect to the following cut-offs for s25OHD: 30,50 , and $75 \mathrm{nmol} / \mathrm{l}$. We have chosen these cut-offs because they have been suggested to be associated with increased risk of various conditions in a number of studies [28].

CFRD, glucose tolerance and $H b A_{1 c}$-defined diabetes mellitus A 75 g OGTT was performed at inclusion in a randomly chosen subgroup of patients who were $\geq 9$ years of age $(n=466)$. OGTT was classified as pathological if $2 \mathrm{~h}$ plasma glucose was $\geq 7.8 \mathrm{mmol} / \mathrm{l}$, thus including patients with both impaired glucose tolerance and CFRD.

Criteria for CFRD diagnosis were: fasting plasma glucose $\geq 7.0 \mathrm{mmol} / \mathrm{l}$ at two occasions, or $2 \mathrm{~h}$ plasma glucose during OGTT $\geq 11.1 \mathrm{mmol} / 1$ at inclusion or any time during follow up at the respective centres. Thus, the group of patients with CFRD includes patients diagnosed by OGTT in the clinic before inclusion in the study ('known CFRD'), and patients diagnosed by OGTT at inclusion ('new CFRD diagnosed by OGTT'). Primarily, the whole group of CFRD patients was analysed, and secondarily the two subgroups were analysed separately for comparison. In patients younger than 9 years of age, the potential presence/absence of CFRD was assessed anamnestically, and OGTT was carried out only in cases where anamnesis raised suspicion of CFRD.

For study purposes, $\mathrm{HbA}_{1 \mathrm{c}}>6.5 \%(>47.5 \mathrm{mmol} / \mathrm{mol})$ at inclusion in patients who had not previously been diagnosed with and treated for diabetes, was used as another criterion for the diagnosis of diabetes ('new DM diagnosed by $\mathrm{HbA}_{\mathrm{lc}}$ ').
$\mathrm{HbA}_{1 \mathrm{c}}$ was measured as per cent of total haemoglobin by ion exchange chromatography with high-performance liquid chromatography at the respective hospital laboratories. The only centre using a different method was Oslo, where $\mathrm{HbA}_{1 \mathrm{c}}$ was measured at the Department for Medical Biochemistry, Oslo University Hospital, by an immunological method (Tina-quant, Roche Diagnostics, Basel, Switzerland). Swedish centres used the Mono S level, while Norwegian and Danish centres used the international National Glycohaemoglobin Standardization Program (NGSP)/ DCCT standard. Therefore, Swedish $\mathrm{HbA}_{1 \mathrm{c}}$ values were transformed using the following formula: $\mathrm{HbA}_{1 \mathrm{c}}$ (NGSP) $(\%)=0.956 \times \mathrm{HbA}_{1 \mathrm{c}}($ Mono S) $(\%)+1.182$.

Confounding factors All variables included in the multiple linear or logistic regression analyses as independent variables were assessed at inclusion in the study. Patients using pancreatic enzymes were classified as pancreatic insufficient. Patients on treatment with ursodeoxycholic acid or those having pathological plasma alanine aminotransferase (ALT) concentration $(>0.76 \mu \mathrm{kat} / \mathrm{l}$ in women, $>1.20 \mu \mathrm{kat} / 1$ in men) were classified as having liver dysfunction. Long-term corticosteroid treatment was classified as 'Yes' if it was being given at the time of inclusion in a longterm manner, either by mouth or inhalation. A lung function test was performed in patients $\geq 7$ years of age using dynamic spirometry at each centre. From measured forced expiratory volume in $1 \mathrm{~s}$ (FEV1), per cent predicted values were calculated using Solymar and Quanjer reference equations for patients $<19$ and $\geq 19$ years, respectively $[29,30]$.

Statistical analysis Because $\mathrm{HbA}_{1 \mathrm{c}}$ values had positively skewed distribution, we log-transformed them (using base $e$ ). Categorical variables were coded (sex male 0/female 1; F508del homozygous genotype 0/other genotypes 1 ; all other variables: no $0 /$ yes 1 [Table 1]). The variable 'country' was coded using two dummy variables (Sweden 0-0; Norway 1-0; Denmark 0-1). Some centres were too small to be used in the statistical analysis and therefore we have controlled for the centre effect by collapsing centres among countries; i.e. variation between countries was used to estimate centre effect. All analyses were primarily conducted for the whole patient dataset $(N=898)$; secondarily the subgroup of children $(n=442)$ and the subgroup of adults $(n=456)$ were analysed separately.

Univariate linear regression analysis was used to examine the relation between vitamin $\mathrm{D}$ status or intake, and $\mathrm{HbA}_{1 \mathrm{c}}$. Multiple linear regression (MLR) analyses were performed for $\mathrm{HbA}_{1 \mathrm{c}}$ as dependent variable, and s25OHD, degree of vitamin $\mathrm{D}$ insufficiency, $\mathrm{s} 25 \mathrm{OHD}<30 \mathrm{nmol} / \mathrm{l}$, $\mathrm{s} 25 \mathrm{OHD}<50 \mathrm{nmol} / 1, \mathrm{~s} 25 \mathrm{OHD}<75 \mathrm{nmol} / \mathrm{l}$, and food and supplemented vitamin D sources of intake as independent variables, each entered separately in various MLR models. 
Table 1 Descriptive statistics for demographic, biochemical and vitamin $\mathrm{D}$ intake data for all the cystic fibrosis patients included in the study $(N=898)$

BW, body weight; DM, diabetes mellitus

\begin{tabular}{|c|c|c|}
\hline Variable & $N$ & \\
\hline \multicolumn{3}{|l|}{ Continuous variables with normal distribution, mean (SD) } \\
\hline FEV1 (\% of predicted) & 802 & $79.0(24.2)$ \\
\hline $\mathrm{s} 25 \mathrm{OHD}(\mathrm{nmol} / \mathrm{l})$ & 788 & $52.0(26.7)$ \\
\hline $\log _{\mathrm{e}} \mathrm{HbA}_{1 \mathrm{c}}$ & 863 & $1.748(0.139)$ \\
\hline \multicolumn{3}{|c|}{ Continuous variables with skewed distribution; median (quartiles) } \\
\hline Age (years) & 898 & $18.3(10.3,29.4)$ \\
\hline $\mathrm{HbA}_{1 \mathrm{c}}(\mathrm{DCCT})(\%)$ & 863 & $5.6(5.3,6.0)$ \\
\hline $\mathrm{HbA}_{1 \mathrm{c}}(\mathrm{IFCC})(\mathrm{mmol} / \mathrm{mol})$ & 863 & $37.7(34.4,42.1)$ \\
\hline Total vitamin D intake $(\mu \mathrm{g})$ & 389 & $17(10.54,26.55)$ \\
\hline Total vitamin $\mathrm{D}$ intake per $\mathrm{kg} \mathrm{BW}(\mu \mathrm{g} / \mathrm{kg})$ & 388 & $0.37(0.20,0.72)$ \\
\hline Food vitamin $\mathrm{D}$ intake $(\mu \mathrm{g})$ & 406 & $4.59(2.95,6.80)$ \\
\hline Food vitamin D intake per kg BW $(\mu \mathrm{g} / \mathrm{kg})$ & 405 & $0.1(0.06,0.17)$ \\
\hline Supplemented vitamin D intake $(\mu \mathrm{g})$ & 730 & $10.00(5.36,20.00)$ \\
\hline Supplemented vitamin D intake per $\mathrm{kg}$ BW $(\mu \mathrm{g} / \mathrm{kg})$ & 729 & $0.24(0.11,0.53)$ \\
\hline \multicolumn{3}{|l|}{ Categorical binomial variables, $n$ (\% yes) } \\
\hline Adult $(\geq 18$ years $)$ & 898 & $456(51)$ \\
\hline Female & 898 & $430(48)$ \\
\hline Use of pancreatic enzymes & 898 & $771(86)$ \\
\hline Long-term corticosteroid treatment & 898 & $299(33)$ \\
\hline Pathological OGTT & 466 & $104(22)$ \\
\hline CFRD & 898 & $88(10)$ \\
\hline Known CFRD & 898 & $41(4.6)$ \\
\hline New CFRD diagnosed by OGTT & 898 & $47(5.2)$ \\
\hline New DM diagnosed by $\mathrm{HbA}_{1 \mathrm{c}}$ & 826 & $76(9.2)$ \\
\hline Liver dysfunction & 884 & $182(21)$ \\
\hline F508del homozygote genotype & 898 & $455(51)$ \\
\hline $\mathrm{s} 25 \mathrm{OHD}<30 \mathrm{nmol} / 1$ & 788 & $155(20)$ \\
\hline $\mathrm{s} 25 \mathrm{OHD}<50 \mathrm{nmol} / 1$ & 788 & $390(49)$ \\
\hline $\mathrm{s} 25 \mathrm{OHD}<75 \mathrm{nmol} / 1$ & 788 & $661(84)$ \\
\hline
\end{tabular}

To evaluate differences in vitamin D status or intake, an independent $t$ test or Mann-Whitney $U$ Test was performed. To compare proportions, a $\chi^{2}$ test was applied. Logistic regression analysis was used to further assess the associations of vitamin D intake or status with CFRD, OGTT or $\mathrm{HbA}_{1 \mathrm{c}}$-defined diabetes. Each MLR or logistic regression model was controlled for country, sex, genotype, age, pancreatic function, FEV1 (\% predicted), liver dysfunction, and long-term corticosteroid treatment.

Statistical analyses used STATISTICA (version 10). All tests were two-sided and $p<0.05$ was considered statistically significant.

\section{Results}

Among the 898 Scandinavian patients with cystic fibrosis aged 0.29-65.9 years, mean s25OHD was $52.0 \mathrm{nmol} / 1$ (range 1.5-206.9 nmol/l). In this patient dataset, s25OHD levels were not determined by latitude zone (zone 1: $54^{\circ}-59^{\circ}$; zone 2: $60^{\circ}-65^{\circ}$; zone $3: 66^{\circ}-71^{\circ}$ north), dark (23 September to 19 March) or light (20 March to 22 September) part of the year, or by belonging to a specific cystic fibrosis centre (NS). Median $\mathrm{HbA}_{1 \mathrm{c}}$ was $5.6 \%(37.7 \mathrm{mmol} / \mathrm{mol})$ and the majority of the patients had physiological OGTT results (Table 1). The adult subpopulation had inferior lung function, greater prevalence of complications including CFRD, and had lower vitamin D intake than the paediatric subpopulation (ESM Table 1).

In the whole patient dataset, univariate linear regression analyses showed significant positive associations between $\mathrm{HbA}_{1 \mathrm{c}}$ and $\mathrm{s} 25 \mathrm{OHD}$, s25OHD $<30 \mathrm{nmol} / \mathrm{l}$, s25OHD $<$ $50 \mathrm{nmol} / \mathrm{l}$, and degree of vitamin $\mathrm{D}$ insufficiency, and significant negative associations between $\mathrm{HbA}_{1 \mathrm{c}}$ and supplemented vitamin $\mathrm{D}$ intake per $\mathrm{kg}$ body weight and total vitamin D intake per $\mathrm{kg}$ body weight. Subgroup analyses for children and adults separately have shown that 
vitamin $\mathrm{D}$ status was associated with $\mathrm{HbA}_{1 \mathrm{c}}$ in the paediatric subpopulation only (ESM Table 2).

We further analysed the whole patient dataset using MLR analysis. In the MLR model of $\mathrm{HbA}_{1 \mathrm{c}}$ controlled for country, age, sex, genotype, lung function, long-term corticosteroid treatment, pancreatic insufficiency, and liver dysfunction, associations remained statistically significant with s25OHD $<30 \mathrm{nmol} / 1$ (ESM Table 3), s25OHD $<50 \mathrm{nmol} / \mathrm{l}$, and vitamin $\mathrm{D}$ insufficiency degree as independent variables (Table 2). Subgroup analyses for children and adults separately have shown that none of the studied vitamin $\mathrm{D}$ variables is associated with $\mathrm{HbA}_{1 \mathrm{c}}$ in adults, whereas $\mathrm{s} 25 \mathrm{OHD}<30 \mathrm{nmol} / 1$ remained significantly associated with $\mathrm{HbA}_{1 \mathrm{c}}$ values in children (ESM Table 4).

Patients with CFRD at inclusion had lower s25OHD, total vitamin $\mathrm{D}$ intake, and supplemented and total vitamin $\mathrm{D}$ intake per kg body weight than non-diabetic patients. Subgroup analyses showed that patients with known CFRD, as opposed to new CFRD, had low vitamin D intake. However, the two subgroups did not differ in s25OHD (low in both). Accordingly, patients with pathological OGTT results had lower s25OHD than patients with physiological OGTT results. Patients with $\mathrm{HbA}_{1 \mathrm{c}}$-defined diabetes had lower supplemented and total vitamin $\mathrm{D}$ intake per kg body weight than patients not meeting the definition of diabetes according to $\mathrm{HbA}_{1 \mathrm{c}}$ (ESM Table 5).

The $\chi^{2}$ test confirmed that inferior serum vitamin $\mathrm{D}$ status is associated with a greater proportion of patients with CFRD, both known and new, pathological OGTT results, or $\mathrm{HbA}_{1 \mathrm{c}}$-defined diabetes (ESM Table 6). In the logistic regression model we controlled for potential confounders: country, age, sex, genotype, lung function, long-term corticosteroid treatment, pancreatic insufficiency, and liver dysfunction. In this model, $\mathrm{s} 25 \mathrm{OHD}<30 \mathrm{nmol} / 1$ and degree of vitamin D insufficiency remained significantly associated with CFRD (Table 3 and ESM Table 7). Similarly, $\mathrm{s} 25 \mathrm{OHD}<50 \mathrm{nmol} / 1$ was associated with $\mathrm{CFRD}$, but statistical significance was not reached $(p=0.058$; Table 3$)$. There was no association between vitamin $\mathrm{D}$ and the two CFRD subgroups (known and new CFRD). Neither pathological OGTT nor $\mathrm{HbA}_{1 \mathrm{c}}$-defined diabetes showed any association with vitamin $\mathrm{D}$ in multivariate logistic regression analysis (ESM Table 8). Since all but 14 diabetic patients were adults, we did not carry out subgroup analyses for children and adults separately.

\section{Discussion}

Here we show that vitamin $\mathrm{D}$ status is associated with $\mathrm{HbA}_{1 \mathrm{c}}$ and CFRD diagnosis in a large cohort of welldefined Scandinavian patients with cystic fibrosis. This is the first report on a relationship between vitamin D and diabetes in a population of patients with cystic fibrosis. Our study leads us to hypothesise that improving vitamin D status in cystic fibrosis patients may have some glucoselowering effect. Interestingly, our results indicate that the effect might be more relevant in the population of children, compared with adults.

Over the past decade, increasing animal and human data in the literature has been suggesting that vitamin D deficiency plays a role in the pathophysiology of diabetes

Table 2 Results of multiple linear regression analyses of vitamin $\mathrm{D}$ status or intake and $\mathrm{HbA}_{1 \mathrm{c}}$ in the whole patient dataset

\begin{tabular}{|c|c|c|c|c|}
\hline Independent variables & $N$ & Adjusted $\mathrm{R}^{2}$ & $\beta^{\mathrm{a}}(\%)(95 \% \mathrm{CI})$ & $p$ value \\
\hline s25OHD (nmol/1) & 692 & 0.202 & $0.0(-0.1,0.0)$ & 0.167 \\
\hline $\mathrm{s} 25 \mathrm{OHD}<30 \mathrm{nmol} / 1$ (0 no, 1 yes $)$ & 692 & 0.205 & $2.6(0.3,4.9)$ & 0.027 \\
\hline $\mathrm{s} 25 \mathrm{OHD}<50 \mathrm{nmol} / 1$ (0 no, 1 yes $)$ & 692 & 0.204 & $1.9(0.1,3.8)$ & 0.042 \\
\hline $\mathrm{s} 25 \mathrm{OHD}<75 \mathrm{nmol} / 1$ (0 no, 1 yes $)$ & 692 & 0.200 & $0.5(-2.0,3.2)$ & 0.681 \\
\hline Vitamin D insufficiency degree ( 0 or 1 or 2 or 3 ) & 692 & 0.205 & $1.0(0.1,2.0)$ & 0.034 \\
\hline Food vitamin $\mathrm{D}(\mu \mathrm{g})$ & 376 & 0.141 & $-0.1(-0.3,0.2)$ & 0.493 \\
\hline Food vitamin $\mathrm{D} / \mathrm{kg} \mathrm{BW}(\mu \mathrm{g} / \mathrm{kg})$ & 376 & 0.142 & $-4.5(-13.0,4.9)$ & 0.337 \\
\hline Supplemented vitamin D $(\mu \mathrm{g})$ & 643 & 0.197 & $0.0(0.0,0.0)$ & 0.509 \\
\hline Supplemented vitamin D/kg BW $(\mu \mathrm{g} / \mathrm{kg})$ & 643 & 0.197 & $-0.2(-1.5,1.1)$ & 0.759 \\
\hline Total vitamin $\mathrm{D}(\mu \mathrm{g})$ & 359 & 0.138 & $0.0(-0.1,0.0)$ & 0.200 \\
\hline Total vitamin $\mathrm{D} / \mathrm{kg} \mathrm{BW}(\mu \mathrm{g} / \mathrm{kg})$ & 359 & 0.135 & $-0.6(-2.1,0.9)$ & 0.399 \\
\hline
\end{tabular}

The models used the same variables, with the exception of the vitamin D terms. The common independent variables include: country, age, sex, genotype, lung function, long-term corticosteroid treatment, pancreatic insufficiency and liver dysfunction

${ }^{a}$ Expressed as the change in $\mathrm{HbA}_{1 \mathrm{c}}$ in percentage points per unit change in the independent vitamin $\mathrm{D}$ variable; to convert $\mathrm{HbA}_{1 \mathrm{c}}$ from percentage units to $\mathrm{mmol} / \mathrm{mol}$, use following conversion formula: IFCC-HbA $1 \mathrm{c}(\mathrm{mmol} / \mathrm{mol})=\left[\mathrm{DCCT}-\mathrm{Hb} \mathrm{A}_{1 \mathrm{c}}(\%)-2.15\right] \times 10.929$

BW, body weight 
Table 3 Multivariable ORs of CFRD diagnosis according to vitamin D status and intake in logistic regression analysis

\begin{tabular}{|c|c|c|c|}
\hline Vitamin D variable & $N$ & $\mathrm{OR}^{\mathrm{a}}(95 \% \mathrm{CI})$ & $p$ value \\
\hline s25OHD (nmol/1) & 712 & $0.99(0.98,1.00)$ & 0.141 \\
\hline $\mathrm{s} 25 \mathrm{OHD}<30 \mathrm{nmol} / 1$ (0 no, 1 yes $)$ & 712 & $1.79(1.02,3.16)$ & 0.042 \\
\hline $\mathrm{s} 25 \mathrm{OHD}<50 \mathrm{nmol} / 1$ (0 no, 1 yes $)$ & 712 & $1.70(0.98,2.95)$ & 0.058 \\
\hline $\mathrm{s} 25 \mathrm{OHD}<75 \mathrm{nmol} / 1$ (0 no, 1 yes $)$ & 712 & $1.41(0.58,3.41)$ & 0.446 \\
\hline Vitamin D insufficiency degree ( 0 or 1 or 2 or 3$)$ & 712 & $1.36^{\mathrm{b}}(1.03,1.79)$ & 0.032 \\
\hline Food vitamin $\mathrm{D}(\mu \mathrm{g})$ & 384 & $0.98(0.89,1.08)$ & 0.668 \\
\hline Food vitamin $\mathrm{D} / \mathrm{kg} \mathrm{BW}(\mu \mathrm{g} / \mathrm{kg})$ & 384 & $0.11(0.002,8.72)$ & 0.326 \\
\hline Supplemented vitamin D ( $\mu \mathrm{g})$ & $-^{\mathrm{c}}$ & $-^{\mathrm{c}}$ & $-^{\mathrm{c}}$ \\
\hline Supplemented vitamin D/kg BW ( $\mu \mathrm{g} / \mathrm{kg})$ & 663 & $0.66(0.38,1.16)$ & 0.147 \\
\hline Total vitamin $\mathrm{D}(\mu \mathrm{g})$ & $-^{\mathrm{c}}$ & $--^{\mathrm{c}}$ & $-^{c}$ \\
\hline Total vitamin $\mathrm{D} / \mathrm{kg} \mathrm{BW}(\mu \mathrm{g} / \mathrm{kg})$ & 367 & $0.52(0.23,1.15)$ & 0.105 \\
\hline
\end{tabular}

${ }^{\text {a }}$ OR for unit change, adjusted for country, age, sex, genotype, lung function, long-term corticosteroid treatment, pancreatic insufficiency, and liver dysfunction

${ }^{\mathrm{b}}$ OR for one unit change; one unit here being one degree (i.e. one unit change is change from 0 to 1 , or 1 to 2 , or 2 to 3 )

${ }^{\mathrm{c}}$ No solution available for equation as data were redundant

BW, body weight

mellitus. Support exists for the hypothesis of a relationship between hypovitaminosis $\mathrm{D}$ and type 2 diabetes, overweight, hypertension, heart infarction and stroke [31-35], exerting its effect via influencing inflammatory atherosclerotic processes [36], peripheral insulin sensitivity and beta cell function [14]. Lower vitamin D levels were found to be associated with insulin resistance and increase in $\mathrm{HbA}_{1 \mathrm{c}}$ $[37,38]$. In type 1 diabetes, vitamin $\mathrm{D}$ is proposed to act through immunological mechanisms by downregulation of dendritic cells and T helper 1 lymphocytes, suppression of antigen-presenting capacity of macrophages and promotion of T helper 2 lymphocytes [31].

CFRD is a unique type of diabetes. Its complete aetiology remains unclear. However, it is known that CFRD is characterised primarily by insulin deficiency and secondarily by insulin resistance [20, 21]. Therefore, vitamin D might theoretically exert certain glucose-lowering effects even in this type of diabetes. The results of our study support this hypothesis. Indeed, in univariate analyses, both vitamin $\mathrm{D}$ status and intake were associated with $\mathrm{HbA}_{1 \mathrm{c}}$ values. Accordingly, CFRD patients had inferior vitamin $\mathrm{D}$ status and lower vitamin $\mathrm{D}$ intake than nondiabetic patients and degree 3 of vitamin $\mathrm{D}$ insufficiency was associated with CFRD, pathological OGTT result and $\mathrm{HbA}_{1 \mathrm{c}}$-defined diabetes.

$\mathrm{HbA}_{1 \mathrm{c}}$ mirrors the long-term glycaemic exposure in patients with or without diabetes. In our study we used it as a proxy for glucose homeostasis. Therefore, in the MLR model we corrected for factors that were previously shown to be independently associated with increased risk of impaired glucose homeostasis and additional diagnosis of diabetes in cystic fibrosis. These are genotype [39], increasing age, female sex, inferior pulmonary function, liver dysfunction, pancreatic insufficiency, and long-term oral or inhalatory corticosteroid use [40]. To account for the potential differences between the participating countries, the 'country' variable was included in the MLR model as an independent variable.

In our MLR models we have confirmed age, lung function, pancreatic insufficiency, country, s25OHD $<30 \mathrm{nmol} / \mathrm{l}$, $\mathrm{s} 25 \mathrm{OHD}<50 \mathrm{nmol} / 1$ and degree of vitamin $\mathrm{D}$ insufficiency as significant determinants of $\mathrm{HbA}_{1 \mathrm{c}}$ values in the Scandinavian cystic fibrosis patients. Similarly, in the logistic regression model that used the same independent variables as the MLR models, risk factors for CFRD were confirmed to be age, lung function, pancreatic insufficiency, country, s25OHD $<30 \mathrm{nmol} / 1$ and vitamin D insufficiency degree. These results are in line with several other studies exploring risk factors for CFRD. However, the findings of $\mathrm{s} 25 \mathrm{OHD}<30 \mathrm{nmol} / \mathrm{l}, \mathrm{s} 25 \mathrm{OHD}<50 \mathrm{nmol} / 1$ and degree of vitamin $\mathrm{D}$ insufficiency as significant independent risk factors for higher $\mathrm{HbA}_{1 \mathrm{c}}$ values and diagnosis of CFRD are novel and indicate for the first time that vitamin $\mathrm{D}$ may play a role both in glucose homeostasis in cystic fibrosis patients as well as in the development of CFRD.

Worldwide, the currently used vitamin D supplementation regimen has not been able to correct vitamin $\mathrm{D}$ insufficiency in cystic fibrosis [7]. This was confirmed in our study, since the vast majority of the patients included had suboptimal s25OHD despite the fact that the median daily total vitamin D intake approached doses previously shown to have a beneficial effect on bone health in certain populations [41]. However, there is yet no evidence of benefit of vitamin D supplementation in cystic fibrosis [8]. 
Thus, our findings are significant since they deliver a hypothesis of a novel field of importance of vitamin D in cystic fibrosis and strongly substantiate prospective intervention studies. In the end, this may also help to outline future prevention and treatment strategies for CFRD.

Important to note, the subgroup analyses for $\mathrm{HbA}_{1 \mathrm{c}}$ have shown that the observed associations are accounted for by associations in the population of children only. This is in line with animal studies [42, 43] and several other human epidemiological studies [44-46] that point to the importance of vitamin D in early childhood. Our data indicate that vitamin D supplementation may be most beneficial during childhood even in cystic fibrosis patients. We speculate that children with cystic fibrosis have more preserved insulin secretion and greater peripheral insulin sensitivity as a result of lower inflammation grade, thus having greater potential for the glucose-lowering effect of vitamin D.

Interestingly, our multivariate models showed associations between $\mathrm{HbA}_{1 \mathrm{c}}$ /diabetes and serum vitamin $\mathrm{D}$ status, but not vitamin $\mathrm{D}$ intake. We speculate that vitamin $\mathrm{D}$ intake may be strongly dependent on adherence with cystic fibrosis treatment, and by correcting for lung function, a probable partial correlate of adherence in cystic fibrosis patients, the associations seen in uncorrected univariate analyses disappear. On the other hand, s25OHD is not as strongly determined by adherence; other important determinants of variation in s25OHD are sun exposure and genetic background, determining the efficacy of vitamin D uptake from the gut and hydroxylation process.

By including lung function in the MLR model, we may have partially corrected for the potential confounding effect of adherence. However, since there is no existing clear measure of adherence to treatment in cystic fibrosis, complete correction for adherence is impossible. Thus, adherence as a hypothetical confounder cannot be fully ruled out.

The Scandinavian Cystic Fibrosis Nutritional Study was not designed for the specific study of diabetes; thus we do not have data on C-peptide, fasting plasma glucose, peripheral insulin sensitivity or the gas chromatographymass spectrometry metabolic profile. Therefore, this study unfortunately cannot address the question of underlying mechanisms behind the associations found. Another limitation of this study is the failure to obtain a full data set; in particular, dietary data and OGTT results are available for a relatively small proportion. Additionally, missing data on fasting plasma glucose may have led to underestimation of both glucose intolerance and CFRD. Similarly, performing OGTT in patients younger than 9 years of age only if CFRD is clinically suspected may have resulted in the underestimation of CFRD and glucose intolerance. Finally, the observational character of the study only allows us to create hypotheses. However, our study clearly indicates that there is a need for intervention studies in order to determine whether the relationships between vitamin $\mathrm{D}$ and $\mathrm{CFRD} / \mathrm{HbA}_{1 \mathrm{c}}$ values found in our study are causal.

Cystic fibrosis is a progressive disease. The risk of developing diabetes is higher with increasing age. Simultaneously, vitamin D absorption from the gut is agedependent. The possibility that the associations seen would mirror the natural progress of the disease can be ruled out since, in the MLR and logistic regression analyses, we corrected for age and even for lung function, a strong correlate of disease progression.

The currently recommended s25OHD concentration for the general population is $\geq 75 \mathrm{nmol} / \mathrm{l}$. It is referred to as optimal and is based on parathyroid hormone response. The results of our study do not support the notion that s25OHD levels below $75 \mathrm{nmol} / 1$ are associated with higher $\mathrm{HbA}_{1 \mathrm{c}}$ values or CFRD diagnosis. However, only $16 \%$ of the cystic fibrosis patients included in our study had optimal s25OHD concentration. Therefore, the statistical analyses comparing this small group of patients with any other group might lack the statistical power necessary to detect any difference. The literature suggests that there is a steep decrease in $\mathrm{HbA}_{1 \mathrm{c}}$ level by increasing s25OHD up to $65 \mathrm{nmol} / \mathrm{l}$ and only smaller decreases with further increases in s25OHD [37]. Indeed, this study shows that $\mathrm{s} 25 \mathrm{OHD}<30 \mathrm{nmol} / 1$ and even $\mathrm{s} 25 \mathrm{OHD}<50 \mathrm{nmol} / 1$ are undisputedly associated with increased $\mathrm{HbA}_{1 \mathrm{c}}$ value and diabetes diagnosis, and therefore gives support for the notion that vitamin $\mathrm{D}$ insufficiency might play a role in the aetiology of diabetes.

A deviant OGTT curve in cystic fibrosis patients is considered to be a precursor of CFRD. Surprisingly, we did not see any association between OGTT result and vitamin $\mathrm{D}$ in the multivariate analyses. We speculate that this might be due to the fact that, unlike CFRD diagnosis, the OGTT result is largely dependent on current disease status, a variable that we did not correct for in the multivariate analyses. On the other hand, patients were in a stable condition with no ongoing exacerbation at inclusion. Thus, the missing association between OGTT result and vitamin $\mathrm{D}$ in our study might suggest that vitamin $\mathrm{D}$ is more strongly related to the risk of developing manifest diabetes than the risk of having isolated impaired glucose tolerance.

In conclusion, the present study supports the hypothesis that vitamin D insufficiency plays a role in the pathogenesis of impaired glucose tolerance and CFRD in cystic fibrosis patients. Degree of vitamin D insufficiency, s25OHD $<$ $30 \mathrm{nmol} / 1$ and $\mathrm{s} 25 \mathrm{OHD}<50 \mathrm{nmol} / \mathrm{l}$ were shown to be associated with higher $\mathrm{HbA}_{1 \mathrm{c}}$ values, and degree of vitamin $\mathrm{D}$ insufficiency as well as $\mathrm{s} 25 \mathrm{OHD}<30 \mathrm{nmol} / \mathrm{l}$ were shown to be significant independent risk factors for CFRD diagnosis in the database of the Scandinavian Cystic Fibrosis Nutritional Study. 
Acknowledgements We thank the cystic fibrosis patients in each centre who have participated in the Scandinavian Cystic Fibrosis Nutritional Study and all the nurses for their practical input into the study. J. Kowalski is acknowledged for reviewing the statistical methods and $\AA$. Nilsson for his feedback on the manuscript. Financial support for this study was provided through the Karolinska Institutet, Norwegian and Swedish Cystic Fibrosis Associations, Swedish Heart Lung Foundation and Stiftelsen Frimurare-Barnhuset i Stockholm. The meetings of the SCFSC have been made possible by an unrestricted grant from Solvay Abbott. This study was further financially supported by the regional agreement on medical training and clinical research (ALF) between Stockholm County Council and the Karolinska Institutet. The funding sources did not participate in the design and conduct of the study, or collection, management, analysis, and interpretation of the data.

Contribution statement TPi and LH designed the study and had the main responsibility for it. TPi analysed the data, interpreted the results and wrote the manuscript with the contribution of LH. KN and IEM analysed the food records. All co-authors enrolled the patients into the study, contributed substantially to the analysis and interpretation of data, critically read and revised the manuscript, and approved the final version of the manuscript to be published.

Duality of interest The authors declare there is no duality of interest associated with this manuscript.

\section{References}

1. Fitz Simmons S (1993) The changing epidemiology of cystic fibrosis. J Pediatr 122:1-9

2. Behrman RE, Kliegman RM (1996) Nelson essentials of pediatrics, 3rd edition. Saunders

3. Levy H, Kalish LA, Huntington I et al (2007) Inflammatory markers of lung disease in adult patients with cystic fibrosis. Pediatr Pulmonol 42:256-262

4. Pincikova T, Hjelte L (2010) Vitamin D status in Stockholm cystic fibrosis patients in 2007-2009. J Cyst Fibros 9(Suppl 1):S91

5. Green DM, Leonard AR, Paranjape SM, Rosenstein BJ, Zeitlin PL, Mogayzel PJ Jr (2010) Transient effectiveness of vitamin D2 therapy in pediatric cystic fibrosis patients. J Cyst Fibros 9:143-149

6. Stephenson A, Brotherwood M, Robert R, Atenafu E, Corey M, Tullis E (2007) Cholecalciferol significantly increases 25hydroxyvitamin D concentrations in adults with cystic fibrosis. Am J Clin Nutr 85:1307-1311

7. Rovner AJ, Stallings VA, Schall JI, Leonard MB, Zemel BS (2007) Vitamin D insufficiency in children, adolescents, and young adults with cystic fibrosis despite routine oral supplementation. Am J Clin Nutr 86:1694-1699

8. Ferguson JH, Chang AB (2009) Vitamin D supplementation for cystic fibrosis. Cochrane Database Syst Rev, Issue 7, Art. No.: CD007298

9. Takiishi T, Gysemans C, Bouillon R, Mathieu C (2010) Vitamin D and diabetes. Endocrinol Metab Clin North Am 39:419-446

10. Hyppönen E, Läärä E, Reunanen A, Järvelin MR, Virtanen SM (2001) Intake of vitamin D and risk of type 1 diabetes: a birth-cohort study. Lancet 358:1500-1513

11. Pittas AG, Sun Q, Manson JE, Dawson-Hughes B, Hu FB (2010) Plasma 25-hydroxyvitamin D concentration and risk of incident type 2 diabetes in women. Diabetes Care 33:2021-2023

12. Danescu LG, Levy S, Levy J (2009) Vitamin D and diabetes mellitus. Endocrine 35:11-17

13. Jeffery LE, Burke F, Mura M et al (2009) 1,25-Dihydroxyvitamin D3 and IL-2 combine to inhibit T cell production of inflammatory cytokines and promote development of regulatory $\mathrm{T}$ cells expressing CTLA-4 and FoxP3. J Immunol 183:5458-5467

14. Chiu KC, Chu A, Go VL, Saad MF (2004) Hypovitaminosis D is associated with insulin resistance and beta cell dysfunction. Am J Clin Nutr 79:820-825

15. Teegarden D, Donkin SS (2009) Vitamin D: emerging new roles in insulin sensitivity. Nutr Res Rev 22:82-92

16. Moran A, Dunitz J, Nathan B, Saeed A, Holme B, Thomas W (2009) Cystic fibrosis-related diabetes: current trends in prevalence, incidence, and mortality. Diabetes Care 32:1626-1631

17. Lanng S, Thorsteinsson B, Nerup J, Koch C (1992) Influence of the development of diabetes mellitus on clinical status in patients with cystic fibrosis. Eur J Pediatr 151:684-687

18. Koch C, Rainisio M, Madessani U et al (2001) Presence of cystic fibrosis-related diabetes mellitus is tightly linked to poor lung function in patients with cystic fibrosis: data from the European Epidemiologic Registry of Cystic Fibrosis. Pediatr Pulmonol 32:343-350

19. Marshall BC, Butler SM, Stoddard M, Moran AM, Liou TG, Morgan WJ (2005) Epidemiology of cystic fibrosis-related diabetes. J Pediatr 146:681-687

20. Nathan BM, Laguna T, Moran A (2010) Recent trends in cystic fibrosis-related diabetes. Curr Opin Endocrinol Diabetes Obes 17:335-341

21. O'Riordan SM, Robinson PD, Donaghue KC, Moran A (2009) Management of cystic fibrosis-related diabetes in children and adolescents. Pediatr Diabetes 10(suppl 12):S43-S50

22. Pincikova T, Nilsson K, Moen IE et al (2011) Inverse relation between vitamin $\mathrm{D}$ and serum total immunoglobulin $\mathrm{G}$ in the Scandinavian Cystic Fibrosis Nutritional Study. Eur J Clin Nutr 65:102-109

23. Lillegaard IT, Andersen LF (2005) Validation of a pre-coded food diary with energy expenditure, comparison of under-reporters v. acceptable reporters. Br J Nutr 94:998-1003

24. Becker W, Lennernas M, Gustafsson IB et al (1998) Precoded food records compared with weighed food records for measuring dietary habits in a population of Swedish adults. Scand J Nutr/ Näringsforskning 42(4):145-149

25. Aksnes L (1994) Simultaneous determination of retinol, alphatocopherol, and 25-hydroxyvitamin D in human serum by highperformance liquid chromatography. J Pediatr Gastroenterol Nutr 18:339-343

26. Lensmeyer GL, Wiebe DA, Binkley N, Drezner MK (2006) HPLC method for 25-hydroxyvitamin D measurement: comparison with contemporary assays. Clin Chem 52:1120-1126

27. Roth HJ, Schmidt-Gayk H, Weber H, Niederau C (2008) Accuracy and clinical implications of seven 25-hydroxyvitamin D methods compared with liquid chromatography-tandem mass spectrometry as a reference. Ann Clin Biochem 45(Pt 2):153-159

28. Holick MF (2007) Vitamin D deficiency. N Engl J Med 19 (357):266-281

29. Solymar L, Aronsson PH, Bake B, Bjure J (1980) Nitrogen single breath test, flow-volume curves and spirometry in healthy children, 7-18 years of age. Eur J Respir Dis 61:275-286

30. Quanjer PH, Tammeling GJ (1983) Summary of recommendations. Standardized lung function testing. Report Working Party, European Community for Coal and Steel. Bull Eur Physiopathol Respir 19:7-10

31. Mathieu C, Gysemans C, Giulietti A, Bouillon R (2005) Vitamin D and diabetes. Diabetologia 48:1247-1257

32. Pittas AG, Lau J, Hu FB, Dawson-Hughes B (2007) The role of vitamin $\mathrm{D}$ and calcium in type 2 diabetes. A systematic review and meta-analysis. J Clin Endocrinol Metab 92:2017-2029

33. Pittas AG, Dawson-Hughes B, Li T et al (2006) Vitamin D and calcium intake in relation to type 2 diabetes in women. Diabetes Care 29:650-656

34. Poole KE, Loveridge N, Barker PJ et al (2006) Reduced vitamin D in acute stroke. Stroke 37:243-245 
35. Suzuki A, Kotake M, Ono Y et al (2006) Hypovitaminosis D in type 2 diabetes mellitus: Association with microvascular complications and type of treatment. Endocr J 53:503-510

36. Timms PM, Mannan N, Hitman GA et al (2002) Circulating MMP9, vitamin D and variation in the TIMP-1 response with VDR genotype: mechanisms for inflammatory damage in chronic disorders? QJM 95:787-796

37. Hyppönen E, Power C (2006) Vitamin D status and glucose homeostasis in the 1958 British birth cohort. Diabetes Care 29:2244-2246

38. Lind L, Hanni A, Lithell H, Hvarfner A, Sorensen OH, Ljunghall S (1995) Vitamin D is related to blood pressure and other cardiovascular risk factors in middle-aged men. Am J Hypertens 8:894-901

39. Cotellessa M, Minicucci L, Diana MC et al (2000) Phenotype/ genotype correlation and cystic fibrosis related diabetes mellitus (Italian Multicenter Study). Pediatr Endocrinol Metab 13:1087-1093

40. Adler AI, Shine BS, Chamnan P, Haworth CS, Bilton D (2008) Genetic determinants and epidemiology of cystic fibrosis-related diabetes: results from a British cohort of children and adults. Diabetes Care 31:1789-1794

41. Cranney A, Horsley T, O’Donnell S et al (2007) Effectiveness and safety of vitamin D in relation to bone health. Evid Rep Technol Assess (Full Rep) 158:1-235

42. Giulietti A, Gysemans C, Stoffels K et al (2004) Vitamin D deficiency in early life accelerates type 1 diabetes in non-obese diabetic mice. Diabetologia 47:451-462

43. Mathieu C, Waer M, Laureys J, Rutgeerts O, Bouillon R (1994) Prevention of autoimmune diabetes in NOD mice by 1,25 dihydroxyvitamin D3. Diabetologia 37:552-558

44. The EURODIAB Substudy 2 Study Group (1999) Vitamin D supplement in early childhood and risk for type I (insulin-dependent) diabetes mellitus. Diabetologia 42:51-54

45. Stene LC, Ulriksen J, Magnus P, Joner G (2000) Use of cod liver oil during pregnancy associated with lower risk of type I diabetes in the offspring. Diabetologia 43:1093-1098

46. Harris S (2002) Can vitamin D supplementation in infancy prevent type 1 diabetes? Nutr Rev 60:118-121 